\title{
EXPERIÊNCIA DE ENSINO REMOTO EMERGENCIAL NA PÓS- GRADUAÇÃO EM ENGENHARIA
}

Clarissa Notariano Biotto - clarissa.biotto@ufscar.br

Sheyla Mara Baptista Serra - sheylabs@ufscar.br

Universidade Federal de São Carlos (UFSCar), Programa de Pós-graduação em Engenharia Civil (PPGECiv), Departamento de Engenharia Civil (DECiv), Rod. Washington Luis km 235 !3.565-905 - São Carlos - SP

Resumo: A pandemia de COVID-19 trouxe desafios para o ensino nas instituições de ensino superior em todo o mundo. Neste cenário de grandes incertezas quanto à segurança sanitária de estudantes e professores, o ensino remoto emergencial tem sido uma opção adotada por diversos cursos para continuar as atividades educacionais e minimizar os impactos do distanciamento social. Assim, este artigo visa relatar a experiência de duas disciplinas de pós-graduação em engenharia civil de uma instituição pública de ensino superior. Por meio de um estudo de caso exploratório, as disciplinas foram adaptadas do modo presencial para remoto e síncrono utilizando programas de comunicação remota e de interação com os participantes. Após um trimestre letivo com dez aulas virtuais, os discentes foram convidados a responder um questionário de avaliação das disciplinas. Os resultados mostraram que as ferramentas cumpriram um papel importante em conectar os docentes e estudantes, entretanto, os discentes não conseguiram superar o impacto psicológico que a pandemia teve sobre a sua saúde mental e motivá-los ao estudo num ambiente de distanciamento social.

Palavras-chave: Ensino remoto emergencial. Pós-graduação. Pandemia. COVID-19.

\section{INTRODUÇÃO}

A suspensão das atividades letivas presenciais devido à pandemia de COVID-19 por todo o mundo, gerou a obrigatoriedade dos professores e estudantes migrarem para a realidade online, transferindo e transpondo metodologias e práticas pedagógicas típicas dos territórios físicos de aprendizagem, naquilo que tem sido designado por ensino remoto de emergência ou emergencial (MOREIRA et al., 2020; ARRUDA, 2020; BARBOSA et al., 2020).

As instituições de ensino superior no Brasil foram fechadas por determinação do Ministério da Educação (MEC) que emitiu a Portaria 343 de 17 de março de 2020 (BRASIL, 2020), que autorizou a substituição das aulas presenciais nas instituições de ensino do país, por aulas que favoreçam os meios e as tecnologias de informação e comunicação. De um modo geral, o incentivo governamental foi para que as aulas e as atividades previstas para serem realizadas presencialmente pudessem ser realizadas de forma remota e pontual, basicamente aplicando o ensino presencial com apoio de plataformas e tecnologias digitais.

Para Moreira et al. (2020), o uso da tecnologia viabilizou o surgimento de novas formas de conexão e distintos métodos de avaliação do processo de ensino e aprendizagem, com recursos diversos, como avaliação de trabalhos de cooperação ou de registro individual de resultados, formas variadas de entrega e apresentação do conteúdo programático. As ferramentas digitais, como: Microsoft Teams, Google Meet, Zoom, Hangouts, Duo, entre outras, passaram a ser utilizadas nos ambientes acadêmicos, antes restritos aos empresariais. 
Em pesquisa realizada com instituições de ensino superior, Arruda (2020) identificou que a maioria delas buscou implementar estratégias de ensino remoto, de maneira que as aulas fossem transmitidas em tempo instantâneo por sistemas de web conferências, as chamadas lives. Com isso, foi possível reproduzir um ambiente que permitiu que professores e estudantes tivessem condições de realizar interações e organizarem seus tempos de aprendizagem da forma mais próxima à educação presencial.

Entretanto, a forma como ocorreu essa transição não foi desenhada previamente, surgindo dúvidas como conceber o ambiente virtual de ensino e aprendizagem. Em vários casos, a decisão dependia de experiências anteriores e discussões atuais, tais como: Como planejar as aulas e atividades online? Como optar pela forma de comunicação entre professores e discentes? Se haveria alternância entre estas formas de comunicação? Como adaptar as atividades dirigidas e o sistema de avaliação do aprendizado? Assim, observa-se que existem diversas questões que serão mais bem respondidas durante o desenvolvimento das disciplinas.

Este artigo objetiva apresentar a experiência de duas disciplinas de pós-graduação em instituição federal de ensino superior oferecidas na forma de ensino remoto emergencial. As disciplinas foram: (1) Modelagem BIM 4D para Gestão da Produção na Construção e (2) Construção Enxuta. As disciplinas foram adaptadas do ensino presencial para remoto em um curto espaço de tempo, sendo avaliadas pelos discentes próximo ao término do período letivo.

\section{ENSINO REMOTO}

\subsection{Ensino mediado por tecnologias digitais}

Segundo Moreira e Schlemmer (2020), a educação mediada pelos recursos digitais faz parte de um novo ecossistema educativo que muito tem contribuído para a reconceitualização dos processos de ensino e de aprendizagem, contextualizado pelo momento histórico e tecnologias disponíveis. Para esses autores, existem terminologias diferentes para conceitos muito semelhantes dependendo se o foco é mais nos aspectos tecnológicos ou mais próximo do potencial pedagógico. O Quadro 1 apresenta um resumo das terminologias e estratégias.

Para que o processo de ensino-aprendizagem possa ser otimizado, segundo Barbosa et al. (2020), os profissionais de ensino devem ser esclarecidos sobre os diferentes conceitos existentes e serem capacitados para desenvolver habilidades para interagir com as tecnologias digitais da informação e comunicação (TDIC) disponibilizadas atualmente.

\subsection{Interação síncrona $\mathrm{x}$ assíncrona}

Mabrito (2006) apresenta que a interação no ambiente de ensino digital pode ocorrer de três diferentes naturezas: aluno e conteúdo, aluno e professor/tutor, aluno e aluno. Em todas as opções, as comunicações são mediadas pelo computador, podendo ser adotadas duas principais estratégias de interação: síncrona ou assíncrona.

Para Mantovani et al. (2013), a interação pode ocorrer de forma síncrona (tempo real) ou assíncrona (em tempo não real), tanto para a comunicação quanto para o acompanhamento dos estudantes. Na modalidade síncrona, a comunicação ocorre de forma simultânea, ou seja, estudantes e professores ou tutores se comunicam em tempo real. A comunicação assíncrona não requer a participação simultânea das partes, oferecendo maior flexibilidade de horário conforme a disponibilidade do discente. Continuando Mantovani et al. (2013), comentam que o ensino síncrono permite a criação de maior coesão na turma e estabelece um ritmo de contato que pode ser mais importante em determinadas culturas.

Segundo Dotta et al. (2013), a opção pelo modelo síncrono se apoia em uma adaptação dos cursos presenciais, sendo que os principais exemplos de recursos síncronos são: telefone, chat, vídeo conferência, web conferência. Em cursos de e-learning corporativo o modelo 
assíncrono pode ser mais utilizado, pois trazem em sua essência o autotreinamento, onde cada aluno poderá desenvolver o seu próprio tempo de aprendizagem. Os principais exemplos de recursos assíncronos são e-mail e fórum.

Quadro 1 - Resumo de terminologias e estratégias possíveis de ensino e aprendizagem

\begin{tabular}{|c|c|}
\hline Estratégias & Características \\
\hline $\begin{array}{l}\text { Educação } \\
\text { presencial } \\
\text { enriquecida com } \\
\text { meios digitais }\end{array}$ & $\begin{array}{l}\text { Os processos de ensino e de aprendizagem (PEA) são desenvolvidos no mesmo espaço } \\
\text { geográfico, com presença física e enriquecidos por diferentes dispositivos e tecnologias } \\
\text { digitais (TD), as quais podem variar em frequência e intensidade. Pode envolver dispositivos } \\
\text { fixos e móveis, robótica, wearables, jogos digitais, QRCodes, dentre outros. }\end{array}$ \\
\hline $\begin{array}{l}\text { Ensino a } \\
\text { Distância }\end{array}$ & $\begin{array}{l}\text { Os PEA ocorrem com separação física e, por vezes, temporal, entre estudantes e professores. } \\
\text { Comunicação baseada na escrita, sendo primeira referência o estudo por correspondência; } \\
\text { posteriormente, o ensino ocorreu via rádio ou televisão, com a oferta de cursos supletivos a } \\
\text { distância, no modelo de teleducação, com aulas via satélite com kits de materiais impressos. }\end{array}$ \\
\hline $\begin{array}{c}\text { Ensino remoto ou } \\
\text { aula remota }\end{array}$ & $\begin{array}{l}\text { Adaptação do ensino presencial físico (mesmas disciplinas, currículo, metodologias e } \\
\text { práticas pedagógicas) é transposto para os meios digitais, em rede. O processo é centrado no } \\
\text { conteúdo, que é ministrado pelo mesmo professor da aula presencial física. } \\
\text { Comunicação predominantemente bidirecional, do tipo um para muitos, no qual o professor } \\
\text { protagoniza videoaula ou realiza uma aula expositiva por meio de sistemas de web conferên- } \\
\text { cia; o foco está nas informações e nas formas de transmissão dessas informações. }\end{array}$ \\
\hline $\begin{array}{l}\text { Educação a } \\
\text { Distância (EAD) } \\
\text { ou eLearning }\end{array}$ & $\begin{array}{l}\text { Utiliza as tecnologias da Internet para propiciar um amplo conjunto de soluções que } \\
\text { objetivam servir de suporte para que a aprendizagem ocorra. } \\
\text { Trabalha no sentido da construção do conhecimento - atividade do sujeito; a aprendizagem } \\
\text { colaborativa e cooperativa; maior autonomia dos sujeitos no processo de aprendizagem; } \\
\text { desenvolvimento de processo de avaliação continuada e formativa, por meio do uso de } \\
\text { "portfolio"; alto grau de interatividade - utilização de comunicação síncrona e assíncrona; } \\
\text { aumento da tomada de consciência, ampliação da consciência social e desenvolvimento de } \\
\text { uma Inteligência Coletiva. } \\
\text { Comunicação e interação multidirecional, atualização, armazenamento, recuperação, } \\
\text { distribuição e compartilhamento instantâneo da informação; superação dos limites de tempo } \\
\text { e espaço. }\end{array}$ \\
\hline Educação Online & $\begin{array}{l}\text { O foco está na interação, na autoria e co-construção do conhecimento, favorecendo a } \\
\text { aprendizagem colaborativa. O modelo pedagógico, por estar perpassado pela lógica de rede, } \\
\text { é predominantemente interacionista, possibilitando a conexão, a liberação do polo de } \\
\text { emissão, e, consequentemente, instigando a reconfiguração de currículos, metodologias e } \\
\text { práticas pedagógicas, provocando uma mudança de paradigma. } \\
\text { A comunicação é caracterizada por processos de ensino e de aprendizagem que acontecem } \\
\text { totalmente em rede, por meio da comunicação multidirecional possibilitada pelo sinal digital } \\
\text { e viabilizada por diferentes tecnologias digitais. }\end{array}$ \\
\hline Educação Digital & $\begin{array}{c}\text { Os PEA que se constituem no coengendramento com diferentes tecnologias digitais, que } \\
\text { podem ou não estar interligadas por redes de comunicação. Compreende desde processos de } \\
\text { ensino e aprendizagem enriquecidos por tecnologias digitais e/ou redes de comunicação, até } \\
\text { o desenvolvimento de uma educação totalmente online e digital, tendo variabilidade na } \\
\text { frequência e na intensidade tanto de tecnologias digitais, quanto de redes de comunicação. } \\
\text { Preza pela comunicação com conectividade, rapidez, fluidez, apropriação de recursos } \\
\text { abertos e de mídias sociais. }\end{array}$ \\
\hline Educação Híbrida & $\begin{array}{c}\text { Processos de ensino e de aprendizagem desenvolvidos num hibridismo de espaços } \\
\text { (geográficos e digitais), presenças (físicas e digitais), tecnologias (analógicas e digitais), } \\
\text { culturas e modalidades. }\end{array}$ \\
\hline Educação Online & $\begin{array}{c}\text { Processos de ensino e aprendizagem desenvolvidos totalmente em rede, por meio da } \\
\text { comunicação multidirecional, possibilitada pelo sinal digital e viabilizada por diferentes } \\
\text { tecnologias digitais. }\end{array}$ \\
\hline
\end{tabular}

Fonte: Baseado em Moreira e Schlemmer (2020). 


\section{MÉTODO DE PESQUISA}

A estratégia de pesquisa utilizada nesse estudo foi o Estudo de Caso de caráter exploratório, procurando responder à questão: "Como adaptar o conteúdo de uma disciplina presencial para um formato remoto em caráter emergencial?". Para tanto, logo após a suspensão das aulas decorrente da pandemia de COVID-19, as docentes seguiram o seguinte passo a passo, conforme Figura 1: Passo 1. Planejamento de conteúdo das disciplinas que foi composto por: tomada de decisão sobre ministrar as aulas de modo síncrono ou assíncrono; estudo e teste de ferramentas para ensino remoto disponibilizadas pela universidade; adaptação do conteúdo das disciplinas para formato remoto. Em seguida, no Passo 2. Retomada das disciplinas no modo remoto e síncrono, foram definidas as ferramentas para o ambiente virtual. Por fim, foi realizada o último Passo 3. Análise e avaliação dos resultados obtidos nas disciplinas.

$\mathrm{Na}$ fase de avaliação das disciplinas, as docentes desenvolveram um questionário composto por onze questões que abordavam perguntas sobre estado mental dos estudantes durante a quarentena, a dificuldade de aprendizado nos aplicativos utilizados pelas disciplinas e o nível de satisfação dos estudantes mediante o formato remoto e síncrono das disciplinas.

Figura 1 - Processo de pesquisa

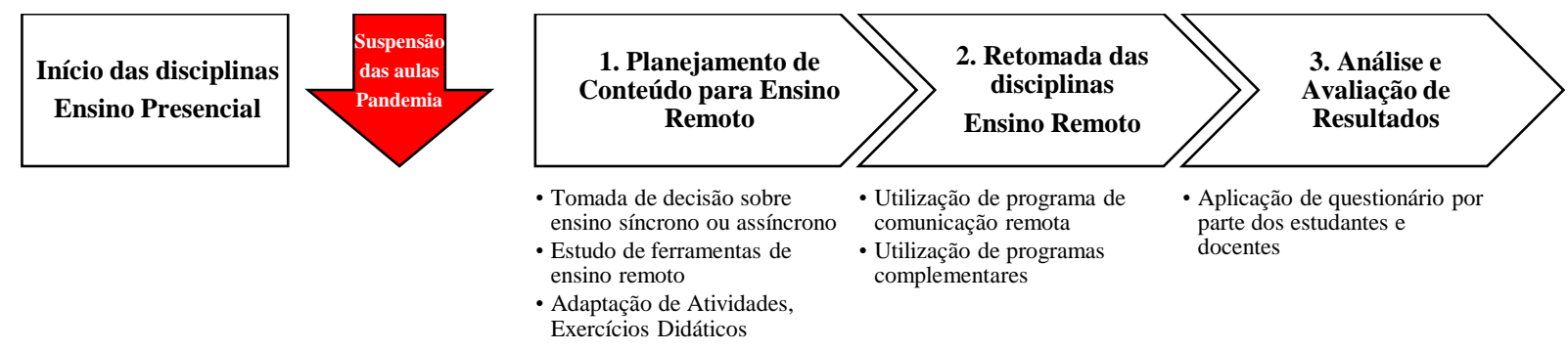

Fonte: Autoras

\subsection{Caracterização das disciplinas}

O estudo exploratório de ensino remoto emergencial foi desenvolvido nas disciplinas de Construção Enxuta e Modelagem BIM 4D para Gestão da Produção da Construção do curso de Pós-Graduação Stricto Sensu em Engenharia Civil de uma Instituição Pública de Ensino Superior. Ambas disciplinas tinham carga horária de 60 horas cada, divididas em 10 semanas, com 3 horas de duração cada aula semanal.

Conforme apresentado, inicialmente as disciplinas seriam desenvolvidas em sala de aula presencial, e deveriam ocorrer entre março a maio de 2020. Entretanto, em função da pandemia de COVID-19 e da suspensão das aulas presenciais, passaram a ser ministradas remotamente entre junho e início de agosto de 2020. Portanto, houve um deslocamento de três meses no início do calendário, conforme Quadro 2.

Quadro 2-Calendário de aulas presenciais e remotas

\begin{tabular}{|c|c|c|}
\hline & Início & Término \\
\hline Calendário Presencial (pré-pandemia) & $11 / 03 / 2020$ & $29 / 05 / 2020$ \\
\hline Calendário Ensino Remoto Emergencial (durante pandemia) & $03 / 06 / 2020$ & $07 / 08 / 2020$ \\
\hline Fonte: Autoras
\end{tabular}

Segundo orientação da Pró-Reitoria de Pós-graduação e do Conselho do Curso de Pósgraduação, foi estabelecido que cada professor poderia decidir se ofereceria a(s) disciplina(s) sob sua responsabilidade e, caso positivo, qual seria a forma de condução das aulas remotas emergenciais. Foi realizada uma reunião virtual com os estudantes a fim de identificar a 
concordância deles com a oferta emergencial e a existência de condições pessoais de cada um para a continuidade das aulas na forma remota. Houve a concordância de todos os estudantes com a oferta nesta modalidade. A disciplina de Construção Enxuta tinha vinte estudantes regularmente inscritos, enquanto a de Modelagem BIM 4D contava com dez estudantes, sendo os estudantes mestrandos e doutorandos.

\section{ESTUDOS EXPLORATÓRIOS}

\subsection{Planejamento de conteúdo para ensino remoto}

O planejamento das disciplinas para formato virtual aconteceu num período de aproximadamente de quatro semanas no mês de maio. Os dois primeiros meses de pandemia foram marcados por incertezas quanto à retomada das atividades e o desenvolvimento de COVID-19 no Brasil e no mundo.

\section{Tomada de decisão sobre ensino síncrono}

Devido ao pouco prazo para desenvolvimento do conteúdo das disciplinas na modalidade de educação a distância, houve adaptação do material de aula preparado para o ensino presencial para o ensino remoto de forma síncrona. Decidido isso, foi iniciada a fase de estudos das ferramentas para ensino remoto.

\section{Estudo de ferramentas para ensino remoto}

As docentes e os estudantes tiveram como recursos disponibilizados pela Instituição: o cadastro institucional via e-mail e acesso a programas de comunicação remota gratuitos para uso acadêmico. Diversos aplicativos foram testados previamente, como por exemplo o Google Meet. Para melhor visualização da reunião nessa ferramenta foi necessária a instalação de plugin (complemento) do programa de comunicação que apresenta a visualização dos participantes da conversa na forma de uma grade ou matriz. Apesar das facilidades deste aplicativo e sua interação com o repositório de arquivos Google ClassRoom, ele não foi utilizado por não apresentar algumas das facilidades que serão descritas a seguir.

O programa escolhido para comunicação foi o Microsoft Teams (MS Teams), também disponível na instituição. O mesmo foi selecionado por possibilitar armazenar em um único ambiente as diferentes formas de comunicação entre os estudantes: a) acesso ao material de aula, como as apresentações e textos para leitura; b) disponibilização de tarefas aos estudantes com a consequente fixação de datas de entrega das atividades solicitadas; c) atribuição das notas de acordo com as tarefas avaliadas; d) gravação e disponibilização dos vídeos das reuniões. Além disso, o programa possibilitava a organização das salas por conteúdo e aulas ministradas, e a interação com outros aplicativos, como formulários e quiz. Outros aplicativos foram testados ao longo do trimestre para promover o engajamento e interação dos estudantes e serão descritos a seguir. Foi necessária a solicitação ao pessoal técnico da instituição a atualização do aplicativo principal para constar recursos ainda não instalados no MS Teams, como calendário, agendamento de reuniões e alteração do plano de fundo.

\section{Adaptação de atividades e exercícios didáticos ao modo remoto}

Devido ao novo formato remoto, a programação das disciplinas teve que ser alterada. Por exemplo, inicialmente a aula de Modelagem BIM 4D tinha exercícios presenciais em sala de aula no qual os estudantes eram divididos em grupos de três estudantes cada, e recebiam folhas no formato $\mathrm{A} 3$, lápis de cor e canetinhas para desenharem. Porém, devido à dificuldade em interagir com os grupos virtualmente, as docentes transformaram o exercício em atividade extra aula para ser feito em dupla e apresentação em aula. Assim, a discussão prévia seria mais intensa entre os estudantes que viriam com ideias formatadas. 


\subsection{Retomada das disciplinas em modo remoto e síncrono}

Durante as aulas remotas, foi solicitado que os estudantes utilizassem recursos próprios como celulares, computadores e internet.

\section{Utilização de programa de comunicação remota}

As disciplinas foram criadas como "Equipes" no MS Teams, compostas pelos estudantes inscritos e as docentes. Além deles, foi possível aceitar "convidados" que acompanharam parte das aulas. Todos deveriam fazer um cadastro prévio no aplicativo a fim de inscrito na disciplina como "membro". Os membros de cada equipe eram adicionados pelo proprietário, no caso, apenas uma das docentes. $\mathrm{O}$ aplicativo determinava o perfil do membro de acordo com o cadastro na universidade, ou seja, os membros que não possuíam e-mails institucionais foram classificados como convidados e tinham permissão de participação restrita.

A Figura 2 mostra as disciplinas criadas no MS Teams que podiam ser visualizadas pelos membros. Quando o aluno seleciona a disciplina de interesse, ele então podia acessar as abas superiores do ambiente geral da disciplina que, por padrão, são: Postagens, Arquivos, Anotações de Classe, Tarefas e Avaliações. Em Postagens, os estudantes tinham acesso a um modo de comunicação na forma de fórum. Entretanto, o aplicativo não possuía a facilidade de deletar as mensagens publicadas. Puderam ser criados canais internos que corresponderem a cada uma das aulas, e reuniam toda comunicação referente àquele tópico da aula (Figura 3).

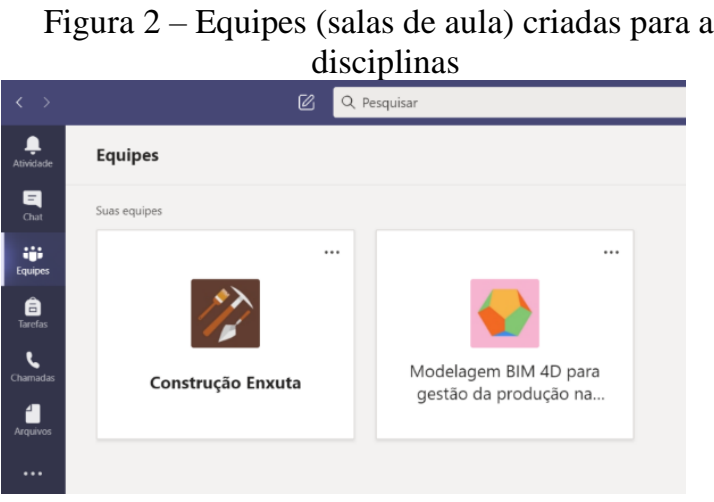

Figura 3 - Ambiente de postagens de comunicação compartilhada na sala de aula e visualização dos canais

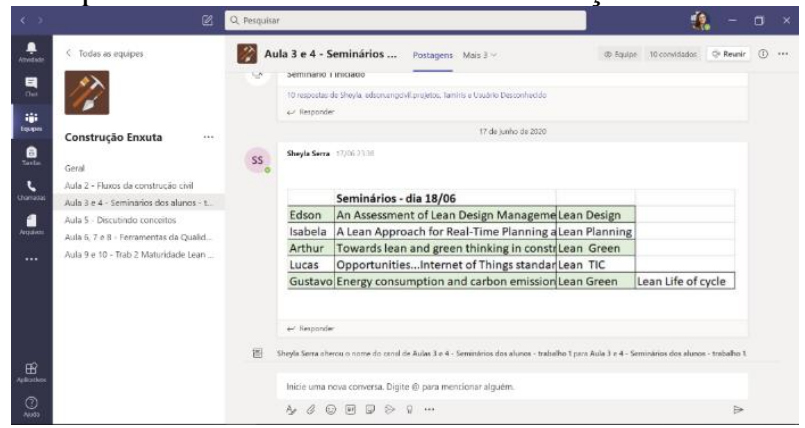

Fonte: Autoras

Novas abas puderam ser adicionadas pelo proprietário, e no caso, formulários foram acrescentados para realização da avaliação das disciplinas, como mostra Figura 4. Também foi adicionada a aba de vídeos, para organização e facilidade de acesso às gravações das aulas, como retratado na Figura 5.

Figura 4 - Utilização de formulário para respostas dos estudantes

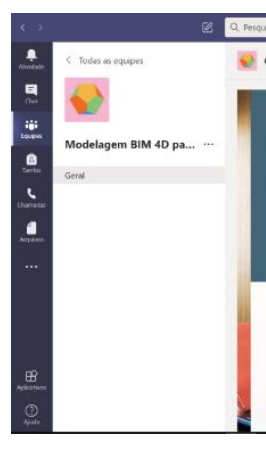

Figura 5 - Canal de disponibilização dos vídeos gerados durante as aulas

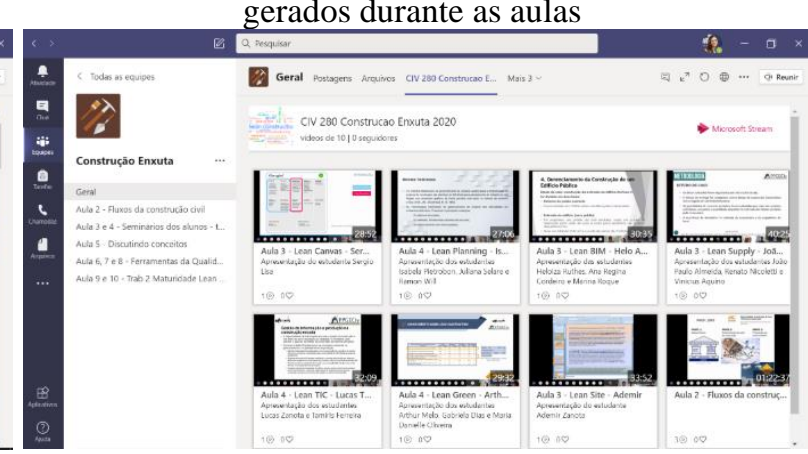

Fonte: Autoras 


\section{Utilização de programas complementares}

Durante a apresentação dos estudantes na aula presencial, foi apresentada aos estudantes a plataforma web Mentimeter e eles foram convidados a acessá-la através de um $Q R$ Code, inserido no primeiro slide da apresentação. Ao escanear o $Q R$ Code, os estudantes foram direcionados para uma página, onde deveriam inserir o código informado pela professora para iniciarem o preenchimento. Após esse processo, os estudantes iniciaram a interação. Nesta aula a aplicação escolhida foi a "Nuvem de Palavras", que funciona como se fosse uma votação, dando mais destaque para palavra que mais se repete nas respostas. O professor pode realizar uma reflexão com cada palavra apresentada, dando preferência às mais repetidas ou maiores. A nuvem gerada pode ser visualizada na Figura 6. Posteriormente, na aula remota de forma síncrona, foi solicitada nova participação via Mentimeter, tendo alcançado resultado semelhante de utilização do programa, conforme Figura 7, sem dificuldade. Como esta segunda nuvem foi realizada ao final da disciplina, pode ser observado que houve apropriação de conteúdo e de terminologias não existentes anteriormente por parte dos estudantes.

Figura 6 - Uso do Mentimeter no ensino presencial

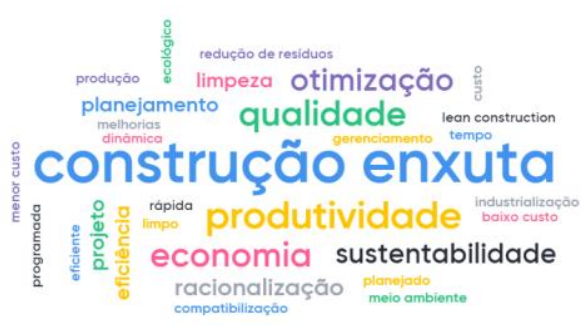

Figura 7 - Uso do Mentimeter no ensino remoto

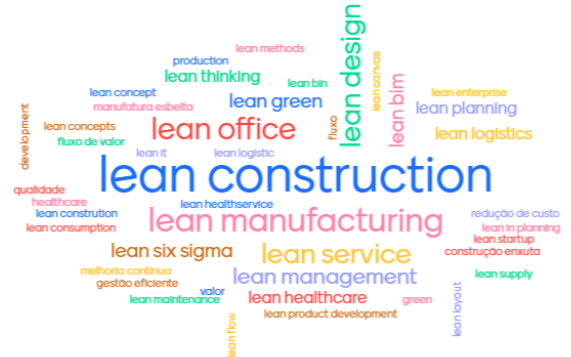

Fonte: Autoras

\subsection{Avaliação e Análise dos Resultados}

A avaliação das disciplinas foi feita por meio de um questionário composto por onze questões. As primeiras quatro perguntas eram relacionadas à saúde mental dos estudantes e os desafios enfrentados para estudar remotamente. As quatro questões seguintes, se referiam ao engajamento de se estudar remotamente quando comparado ao ensino presencial, bem como as dificuldades em se adaptar ao uso das novas ferramentas computacionais. E, por fim, os discentes foram convidados a ranquear as disciplinas e escrever comentários sobre as mesmas. Dos 30 estudantes matriculados, 25 responderam ao questionário.

Quando questionados sobre "Como você está se sentindo durante a pandemia?", quase metade dos estudantes respondeu "aumento de insônia" e "mais confuso", conforme Figura 8. E quanto aos desafios existentes para conduzir o estudo remoto, eles responderam "isolamento social", "muitas distrações", "falta de comunicação com os colegas", e "dificuldade em manter um programação regular" (Figura 9). Quando questionados sobre o grau de satisfação com a atual organização no ensino remoto, $48 \%$ dos estudantes respondeu que estão "um pouco satisfeito" (Figura 10). Não houve relatos de dificuldades quanto à utilização dos recursos próprios e dos equipamentos para estudar remotamente, sendo $100 \%$ das respostas afirmativas para a pergunta "você tem todo o equipamento necessário para estudar remotamente?", conforme Figura 11.

$\mathrm{Na}$ pergunta 5 da Figura 12, 48\% dos estudantes informou que se sentiam menos engajados em estudar na aula remota do que presencialmente, contudo, outros $48 \%$ dos estudantes disse que a participação em ambas modalidades de ensino é igual. Em seguida, se questionou sobre dificuldades enfrentadas para interagir no MS Teams e $72 \%$ dos estudantes relatou que não houve dificuldades em aprender novos aplicativos (Figura 13). 


\section{COBENGE (C) COBENCE 2020 e III Simpósio Internacional de Educação em Engenharia da ABENGE}

\section{"Os desafios para formar hoje o engenheiro do amanhã"}

Figura 8 - Avaliação da parte emocional dos estudantes durante a pandemia

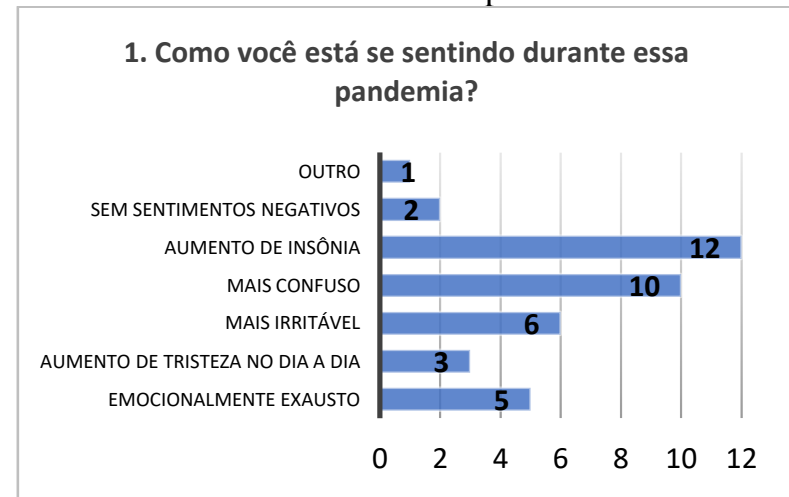

Figura 10 - Avaliação sobre o grau de satisfação dos estudantes quanto sua organização para o ensino remoto

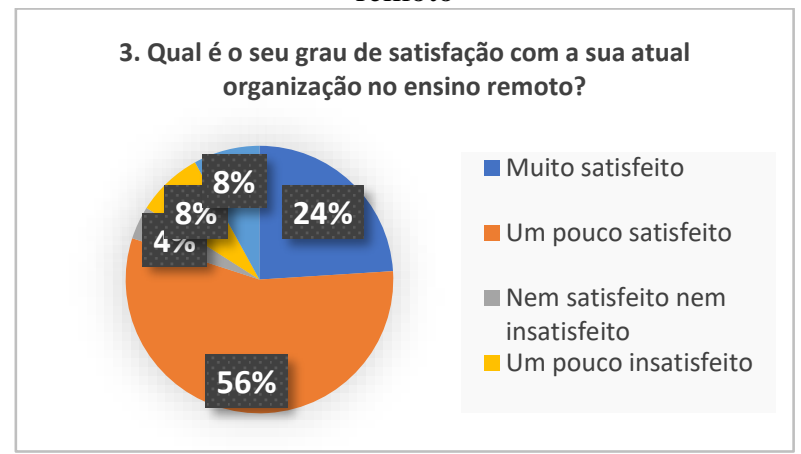

Figura 12 - Avaliação do engajamento e motivação dos estudantes para o ensino remoto

5. Em comparação às aulas presenciais, como você define seu engajamento e participação na aula remota?

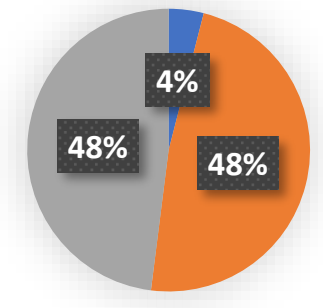

$$
\begin{aligned}
& \text { Me sinto mais engajado } \\
& \text { na aula remota } \\
& \text { Minha participação está } \\
& \text { igual } \\
& \text { Me sinto menos engajado } \\
& \text { na aula remota }
\end{aligned}
$$

Figura 9 - Avaliação dos desafios enfrentado pelos estudantes para conduzir o estudo remotamente

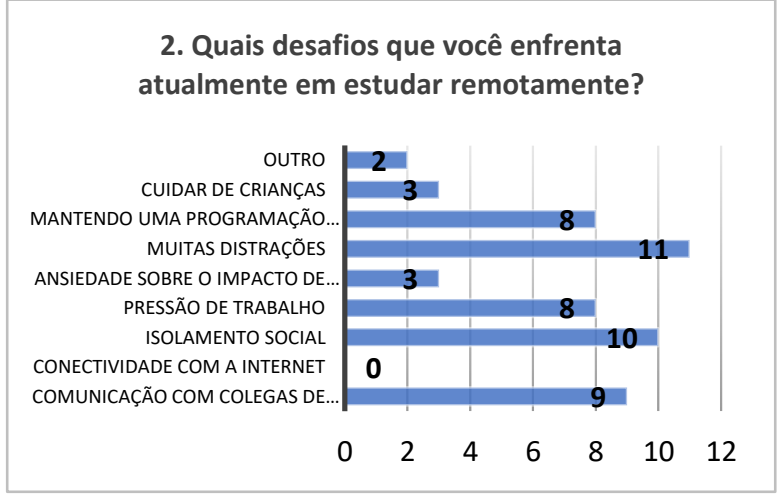

Figura 11 - Avaliação de equipamentos necessários aos estudantes para assistir as aulas remotas

4. Você tem todo o equipamento necessário para estudar remotamente?

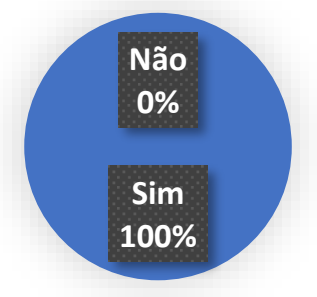

Sim

Não

Figura 13 - Avaliação do Microsoft Teams pelos estudantes das disciplinas

6. Você enfrentou muita dificuldade para aprender usar o Microsoft Teams e demais ferramentas adotadas no ensino remoto?

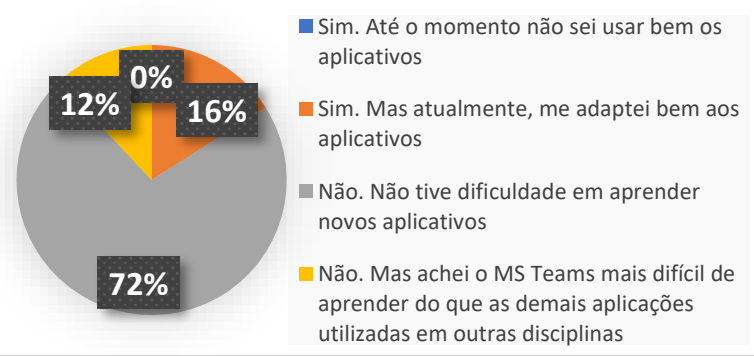

Fonte: Autoras

Na questão 7, os discentes foram questionados sobre o que é melhor no ensino remoto, e $80 \%$ dos estudantes respondeu que é melhor "assistir aulas teóricas", seguido por $44 \%$ que indicou "apresentar trabalhos". Porém, conforme a questão 8, "tirar dúvidas com o professor" (79\%) e "exercícios em sala de aula" (79\%) foram consideradas como atividades mais bem desempenhadas no ensino presencial. O gráfico da Figura 14 mostra o comparativo entre as atividades preferidas pelos estudantes no ensino remoto versus presencial. Na pergunta 9 representada na Figura 15, foi questionado ao aluno qual tipo de ensino remoto ele prefere: síncrono ou assíncrono. 92\% responderam que preferem o ensino síncrono para mantê-los engajados e disciplinados. De maneira geral, as disciplinas adaptadas ao ensino remoto e síncrono obtiveram nota média de 4,04, numa escala de 5, ou seja, bom, conforme Figura 16. 
"Os desafios para formar hoje o engenheiro do amanhã"

Figura 14 - Comparação entre atividades melhor desempenhadas no ensino remoto x presencial

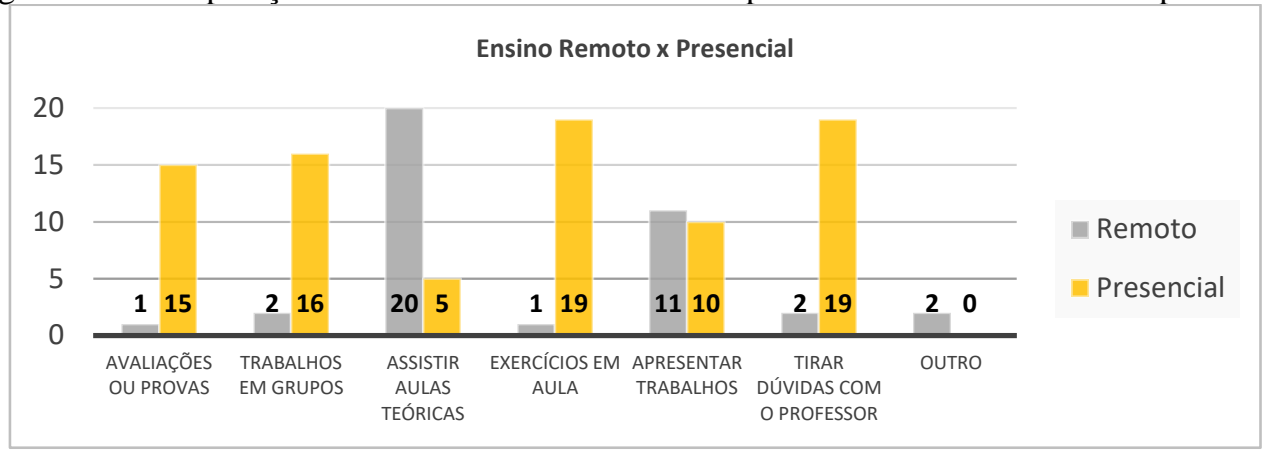

Figura 15 - Avaliação entre aulas síncronas e assíncronas

9. Você preferiria que a disciplina fosse assíncrona?

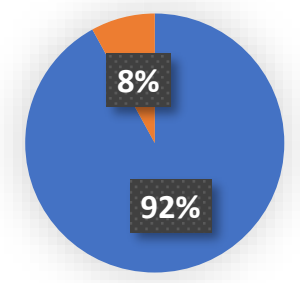

não. Síncrona é melhor para nos manter engajados e disciplinados nos estudos

- Sim. Quando assíncrona tenho mais flexibilidade de horário para assistir a aula e estudar
Figura 16 - Avaliação geral da satisfação dos estudantes nas disciplinas remotas e síncronas

10. De maneira geral, avalie como foi sua experiência no ensino remoto e síncrono nestas disciplinas

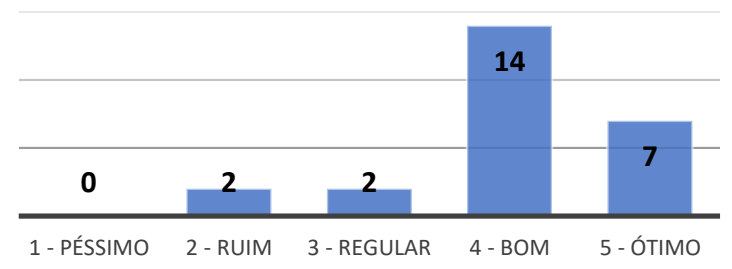

Fonte: Autoras

\section{CONSIDERAÇÕES FINAIS}

A retomada das aulas da pós-graduação apresentadas aconteceu de forma remota emergencial utilizando-se principalmente da adaptação do conteúdo dessas disciplinas da modalidade presencial para o ambiente virtual. O método de planejamento apresentado se mostrou eficiente, considerando as limitações existentes, e pode ser seguido por outras instituições. $\mathrm{Na}$ fase de planejamento do estudo de caso, estudantes e professores testaram ferramentas gratuitas de comunicação remota, até a escolha do programa Microsoft Teams, conforme vantagens apresentadas.

No final do período acadêmico, as disciplinas foram avaliadas pelos estudantes. De maneira geral, os discentes retrataram os seguintes impactos na saúde mental sentidos durante a pandemia: confusão, insônia, exaustão emocional e irritabilidade. Contudo, apesar disso, a organização discente para estudar remotamente foi satisfatória, tendo os estudantes sido aprovados nas disciplinas. As aulas síncronas foram consideradas preferidas pelos estudantes em comparação às aulas assíncronas em outras disciplinas. Isso se deve ao fato das primeiras facilitarem a regularidade e disciplina nos estudos, além de minimizar os impactos do distanciamento social no ensino. A estratégia utilizada foi considerada adequada e futuramente, pós-pandemia, poder-se-á pensar em adotar um modelo de ensino híbrido, no qual aulas teóricas possam ser feitas remotamente.

O aplicativo utilizado cumpriu a função de organizar o conteúdo do ensino remoto, e conectar discentes e docentes. Os resultados mostraram que, apesar das tecnologias utilizadas não terem sido identificadas como barreiras para o engajamento dos estudantes, as ferramentas para ensino virtual não conseguiram superar os impactos da pandemia na saúde mental dos discentes, causando queda de motivação e engajamento. 


\title{
Agradecimentos
}

O presente trabalho foi realizado com apoio da Coordenação de Aperfeiçoamento de Pessoal de Nível Superior - Brasil (CAPES) por meio de bolsa de pós-doutorado via Programa Nacional de Pós-Doutorado (PNPD).

\section{REFERÊNCIAS}

ARRUDA, E.P. Educação Remota Emergencial: elementos para políticas públicas na educação brasileira em tempos de Covid-19. Em Rede - Revista de Educação a Distância, v. 7, n. 1, p. 257-275, 2020. Disponível em: https://www.aunirede.org.br/revista/index.php/emrede/article/view/621

BARBOSA, A.M.; VIEGAS, M.A.S. BATISTA, R.L.N.F.F. Aulas presenciais em tempos de pandemia: relatos de experiências de professores do nível superior sobre as aulas remotas. Revista Augustus, v. 25, n. 51, p. 255 280, 2020. Disponível em: https://revistas.unisuam.edu.br/index.php/revistaaugustus/article/view/565/302

BRASIL. Ministério da Educação. Portaria Nº 343, de 17 de março de 2020: Dispõe sobre a substituição das aulas presenciais por aulas em meios digitais enquanto durar a situação de pandemia do Novo Coronavírus COVID-19. Disponível em: http://www.in.gov.br/en/web/dou/-/portaria-n-343-de-17-de-marco-de-2020248564376

DOTTA, S.; OLIVEIRA, C.A.; JORGE, E.F.C; AGUIAR, P.H.L; SILVEIRA, R.T. Abordagem dialógica para a condução de aulas síncronas em uma web conferência. In: X Congresso Brasileiro de Ensino Superior a Distância (ESUD), 2013, Belém/PA. Anais... UNIREDE. 12p. Disponível em: https://doi.org/10.13140/2.1.3941.6969

MABRITO, M. A study of synchronous versus asynchronous collaboration in an online business writing class. The American Journal of Distance Education, v. 20, n. 2, p. 93-107, 2006. Disponível em: https://doi.org/10.1207/s15389286ajde2002_4

MANTOVANI, D.M.N.; GOUVÊA, M.A.; VIANA, A.B.N. Comunicação síncrona no ensino de Estatística Aplicada à Administração: um estudo em uma disciplina semipresencial. REGE - Revista de Gestão, v. 20, n. 2, p. 165-181, 2013. Disponível em: https://www.sciencedirect.com/science/article/pii/S1809227616302351

MOREIRA, J.A.M.; HENRIQUES, S.; BARROS, D. Transitando de um ensino remoto emergencial para uma educação digital em rede, em tempos de pandemia. Dialogia, São Paulo, n. 34, p. 351-364, Disponível em: https://doi.org/10.5585/Dialogia.N34.17123.

MOREIRA, J.A.; SCHLEMMER, E. Por um novo conceito e paradigma de educação digital onlife. Revista UFG, v. 20, n. 63438, p. 1-35, 2020. https://www.revistas.ufg.br/revistaufg/article/view/63438/34772

\section{EMERGENCY REMOTE EDUCATION EXPERIENCE IN POSTGRADUATE ENGINEERING}

\begin{abstract}
The COVID-19 pandemic has brought several challenges for teaching in higher education institutions worldwide. In this scenario of great uncertainty regarding the health of students and teachers, emergency remote education has been an option adopted by several courses to continue educational activities and minimize the impacts of social distance on teaching. This article aims to report the experience of two postgraduate courses in civil engineering from a public institution of higher education. Through an exploratory case study, the teachers planned to adapt the disciplines from the face-to-face to the remote and synchronous mode using different programs of online communication and interaction with participants. After an academic quarter, students were asked to answer a questionnaire to evaluate them. The results show that the tools played an essential role in connecting teachers and students. However, the students had a psychological impact on their mental health and their motivation for studying in an environment of social distance.
\end{abstract}

Keywords: Emergency remote education. Postgraduate studies. Pandemic. COVID-19. 